late deaths, due to renal damage, did occur in animals given large doses of gold sodium thiosulphate even when protected from early death by BAL. BAL is less effective against the lethal action of similar doses of gold sodium thiomalate. However, the retarded growth rate of young rats given a single non-lethal dose of gold sodium thiosulphate ( $50 \mathrm{mg}$. per kilo) is not observed if a single injection of $3 \cdot 1 \mathrm{mg}$. BAL is given at the same time as the gold. In these animals the microscopical changes in kidney and liver due to gold were also prevented by BAL. Derek R. Wood.

Treatment with Amidopyrine and Diminution in Vitamin K. (Traitement par le pyramidon et diminution de la vitamine K.) Galimard, J.-E. (1947). Bull. Soc. chim. biol., 29, 641.

As amidopyrine is often used in rheumatism, the author investigated its action on blood prothrombin levels. No direct antagonism of vitamin $\mathrm{K}$ by amidopyrine was observed in vitro. Experiments on rabbits showed that amidopyrine, in doses of $0.03 \mathrm{~g}$. per kilo in $5 \%$ solution, causes only a slight fall in prothrombin levels. Four cases of rheumatism treated with amidopyrine are described. In the first, prothrombin levels fell after 8 days' treatment with $0 \cdot 8 \mathrm{~g}$. per day, partly intravenously, but recovered considerably 2 days after treatment ceased. The treatment was started again with addition of a synthetic naphthoquinone derivative, and the prothrombin level increased sharply. A second patient came into hospital with a low prothrombin level, which increased almost to normal after 11 days' treat- ment with salicylates and amidopyrine. Later, the salicylates were omitted and the amidopyrine was increased and the prothrombin level fell. In a third case, also with an originally low prothrombin level, treatment with amidopyrine, by improving the rheumatism, raised that level; continuation of treatment affected the liver and the level fell again, but rose to normal 2 days after stopping the drug. In the fourth case, little effect on prothrombin levels was produced by full doses of amidopyrine. The author concludes that amidopyrine affects the prothrombin level only by acting on the liver, and that this action passes off quickly on stopping the drug, or it may be readily prevented by small amounts of vitamin $\mathbf{K}$.

Reginald St. A. Heathcote.

Antistreptolysin Titration in Acute Iritis. [In English.] BJÖRK, A. (1947). Acta opthalmologica, 25, 127.

This article deals with the determination of the antistreptolysin titre in acute iritis. The principle of the titration is to determine to what degree the serum containing antistreptolysin is able to check haemolysis. By comparative testing with a standard serum it is possible to determine the amount of antistreptolysin units in $1 \mathrm{ml}$. Antistreptolysin titres of up to 200 may be considered normal. The results in a series of 52 cases of acute iritis are tabulated, and it is concluded: (1) that low titres exclude an infection with haemolytic streptococci; (2) that infection with streptococci plays a minor part in acute iritis. This result was unexpected in view of the position which iritides are considered to occupy in rheumatic diseases.

L. Boxer.

\title{
BOOK · REVIEWS
}

Textbook of the Rheumatic Diseases. Edited by W. S. C. Copeman, O.B.E., M.D., F.R.C.P. First Edition. 1948. E. and S. Livingstone Ltd. Edinburgh. Pp. 612; 351 illustrations, some in full colour. Price $50 s$.

The definition of the word " textbook" (if one excludes " a reference book of scriptural texts" and " an opera or other libretto" as inappropriate to this particular occasion) is " a book used as a standard work in any branch or course of study". The assurance inherent in presenting a new book under the title of " Textbook of the Rheumatic Diseases" is, no doubt, justified by the galaxy of talent which Dr. W. S. C. Copeman has brought together under his editorship. The standard of the individual contributions is high, and skilful editing has reduced constant repetition (a most irritating feature of many " edited " productions) to a minimum. When so many " authorities" combine to write on a subject about which comparatively little is known, the end result might be expected to include many brilliant but conflicting theories. This has been avoided for the most part and a genuine attempt has been made to present the known facts which form a most impressive collection when arranged and presented as they are in these pages. Nevertheless, the gaps in our knowledge are so great that theorizing cannot be excluded entirely and, indeed, a certain amount is both stimulating and necessary. It is particularly rife, however, in relation to treatment, and the attempts to justify any line of therapy by theoretical argument tends, on occasion, to cloud rather than clarify the subject.

A valuable orthopaedic contribution serves to emphasize the difference between the theories of much of our conservative therapy and the reasoned practical application of surgical measures of treatment.

The factual presentation of the subject in a book of this standard would be strengthened by the inclusion of a special section dealing with the "rheumatic anatomy" of joints and the anatomy of movement, for a knowledge of local anatomy is essential to an understanding of deformity and its prevention.

The book deals adequately with the psychological factors which present themselves from time to time. Most of the emphasis is placed on the psychology of the patient and very little on that of the doctor. The handling of the chronic sick demands a special approach and a special understanding. It requires not only a scientific appreciation of all the varying aspects of the malady but a personal and sympathetic interest in the individual afflicted with the disease. Possibly a list of "Do's" and "Dont's" for medical men dealing with the problems of this disease group would have been a valuable addition to the book.

It is impossible to do full justice to an important book of this type within the space allotted for this review. There is no doubt that it is a valuable contribution to the literature of the rheumatic diseases and will prove itself essential to all who are concerned in the teaching and management of this increasingly important branch of medicine.

The production, printing, and general presentation leaves nothing to be desired. The illustrations, whether of radiographs, coloured slides, or clinical material, are first class and a great credit to all concerned-not least to the famous Edinburgh Publishing House of E. and S. Livingstone.

J. W. T. Patterson. 